\title{
HIV/AIDS-related stigma and discrimination: A conceptual framework and an agenda for action
}

\author{
Richard Parker \\ Peter Aggleton \\ Kathy Attawell \\ Julie Pulerwitz \\ Population Council \\ Lisanne Brown
}

Follow this and additional works at: https://knowledgecommons.popcouncil.org/departments_sbsr-hiv

Part of the Immunology and Infectious Disease Commons, and the International Public Health Commons

How does access to this work benefit you? Let us know!

\section{Recommended Citation}

Parker, Richard, Peter Aggleton, Kathy Attawell, Julie Pulerwitz, and Lisanne Brown. 2002. "HIV/AIDSrelated stigma and discrimination: A conceptual framework and an agenda for action," Horizons Report. Washington, DC: Population Council. 
HIV/AIDS-related

Stigma and Discrimination: A Conceptual Framework and an Agenda for Action

Horizons Program 


\section{HIV/AIDS-related Stigma and Discrimination: A Conceptual Framework and an Agenda for Action}

Richard Parker and Peter Aggleton

with

Kathy Attawell, Julie Pulerwitz, and Lisanne Brown 


\section{Acknowledgements}

We would like to acknowledge the contribution of Anne Malcolm (Sydney, Australia) and Miriam Maluwa (UNAIDS, Geneva) to our thinking about these issues. Anne undertook one of the first reviews of the forms and determinants of HIV/AIDS-related stigma, discrimination, and denial for WHO/GPA and UNAIDS, elements of which have been utilized here.

USAID This study was supported by the Horizons Program, which is implemented by the Population

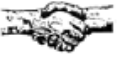
Council in collaboration with the International Center for Research on Women, International HIV/AIDS Alliance, Program for Appropriate Technology in Health, the University of Alabama at Birmingham, Tulane University, Family Health International, and Johns Hopkins University. Horizons is funded by the U.S. Agency for International Development, under the terms of HRNA-00-97-00012-00. The opinions expressed herein are those of the authors and do not necessarily reflect the views of the U.S. Agency for International Development.

Published in May 2002.

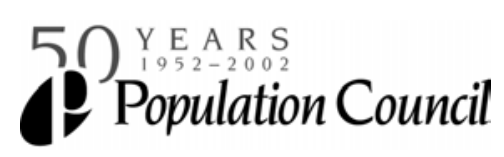

The Population Council is an international, nonprofit, nongovernmental institution that seeks to improve the wellbeing and reproductive health of current and future generations around the world and to help achieve a humane, equitable, and sustainable balance between people and resources. The Council conducts biomedical, social science, and public health research and helps build research capacities in developing countries. Established in 1952, the Council is governed by an international board of trustees. Its New York headquarters supports a global network of regional and country offices.

Copyright $(2002$ The Population Council Inc. 


\section{Table of Contents}

Introduction 1

Analyzing Stigma and Discrimination 1

What are the sources of stigmatization and discrimination? 1

How are stigma and discrimination manifested? 4

Developing a New Conceptual Framework 9

Why do we need a new way of thinking?

Identifying an Agenda for Research and Intervention 11

$\begin{array}{ll}\text { What are the implications for research? } & 11\end{array}$

$\begin{array}{ll}\text { What are the implications for interventions? } & 13\end{array}$

$\begin{array}{ll}\text { Summary } & 15\end{array}$

$\begin{array}{ll}\text { References } & 16\end{array}$ 



\section{Introduction}

In 1987, the late Jonathan Mann, then director of the WHO Global Programme on AIDS, identified three phases of the HIV/AIDS epidemic: the epidemic of HIV, the epidemic of AIDS, and the epidemic of stigma, discrimination, and denial. He noted that the third phase is "as central to the global AIDS challenge as the disease itself" (Mann 1987). Despite international efforts to tackle HIV/AIDS since then, stigma and discrimination (S\&D) remain among the most poorly understood aspects of the epidemic. As recently as 2000, Peter Piot, executive director of UNAIDS, identified stigma as a "continuing challenge" that prevents concerted action at community, national, and global levels (Piot 2000).

This poor understanding is due in part to the complexity and diversity of $\mathrm{S} \& \mathrm{D}$, but also in part to limitations in current thinking within the field and the inadequacy of available theoretical and methodological tools (USAID 2000). The purpose of this paper is to propose a new conceptual framework to help inform thinking about the processes of S\&D, ${ }^{1}$ about the way these processes relate to HIV/AIDS, and about potential interventions to address S\&D and minimize their impact. To do this, the paper:

- Analyzes the sources of S\&D, the ways in which HIV/AIDS-related S\&D manifests itself, and the contexts in which HIV/AIDS-related S\&D take place.

- Highlights the limitations of current thinking and argues that S\&D need to be understood as social rather than individual processes.

- Identifies an agenda for research and intervention.

\section{Analyzing Stigma and Discrimination}

\section{What Are the Sources of Stigmatization and Discrimination?}

To understand the ways in which HIV/AIDS-related S\&D appear and the contexts in which they occur, we first need to understand how they interact with pre-existing S\&D associated with sexuality, gender, race, and poverty (see Figure 1). HIV/AIDS-related S\&D also interact with preexisting fears about contagion and disease. Early AIDS metaphors - as death, as horror, as punishment, as guilt, as shame, as otherness - have exacerbated these fears, reinforcing and legitimizing stigmatization and discrimination.

\footnotetext{
${ }^{1}$ This paper focuses on stigma and discrimination, which have social origins, but does not address the related issue of denial, which has psychological origins and requires analysis using a different conceptual framework.
} 


\section{Hgrizons}

\section{Sexuality}

HIV/AIDS-related S\&D are most closely related to sexual stigma. This is because HIV is mainly sexually transmitted and in most areas of the world, the epidemic initially affected populations whose sexual practices or identities are different from the "norm." HIV/AIDS-related S\&D has therefore appropriated and reinforced pre-existing sexual stigma associated with sexually transmitted diseases, homosexuality, promiscuity, prostitution, and sexual "deviance" (Gagnon and Simon 1973; Plummer 1975; Weeks 1981). The belief that homosexuals are to blame for the epidemic or that homosexuals are the only group at risk of HIV is still common. Promiscuous sexual behavior by women is also commonly believed to be responsible for the heterosexual epidemic, regardless of the epidemiological reality. In Brazil, for example, where surveillance data have shown high rates of HIV infection among monogamous married women, HIV-positive women are still widely perceived to be sexually promiscuous (Parker and Galvão 1996).

\section{Gender}

HIV/AIDS-related S\&D are also linked to gender-related stigma. The impact of HIV/AIDS-related S\&D on women reinforces pre-existing economic, educational, cultural, and social disadvantages and unequal access to information and services (Aggleton and Warwick 1999). In settings where heterosexual transmission is significant, the spread of HIV infection has been associated with female sexual behavior that is not consistent with gender norms. For example, prostitution is widely perceived as non-normative female behavior, and female sex workers are often identified as "vectors" of infection who put at risk their clients and their clients' sexual partners. Equally, in many settings, men are blamed for heterosexual transmission, because of assumptions about male sexual behavior, such as men's preference or need for multiple sexual partners.

\section{Race and ethnicity}

Racial and ethnic S\&D also interact with HIV/AIDS-related S\&D, and the epidemic has been characterized both by racist assumptions about "African sexuality" and by perceptions in the developing world of the West's "immoral behavior." Racial and ethnic S\&D contribute to the marginalization of minority population groups, increasing their vulnerability to HIV/AIDS, which in turn exacerbates stigmatization and discrimination.

\section{Class}

The HIV/AIDS epidemic has developed during a period of rapid globalization and growing polarization between rich and poor (Castells 1996, 1997, 1998). New forms of social exclusion associated with these global changes have reinforced pre-existing social inequalities and stigmatization of the poor, homeless, landless, and jobless. As a result, poverty increases vulnerability to HIV/AIDS, and HIV/AIDS exacerbates poverty (Parker, Easton, and Klein 2000). HIV/AIDS-related S\&D interacts with pre-existing S\&D associated with economic 
marginalization. In some contexts, the epidemic has been characterized by assumptions about the rich, and HIV/AIDS has been associated with affluent lifestyles.

Figure 1 The link between HIVIAIDS and pre-existing sources of S\&D

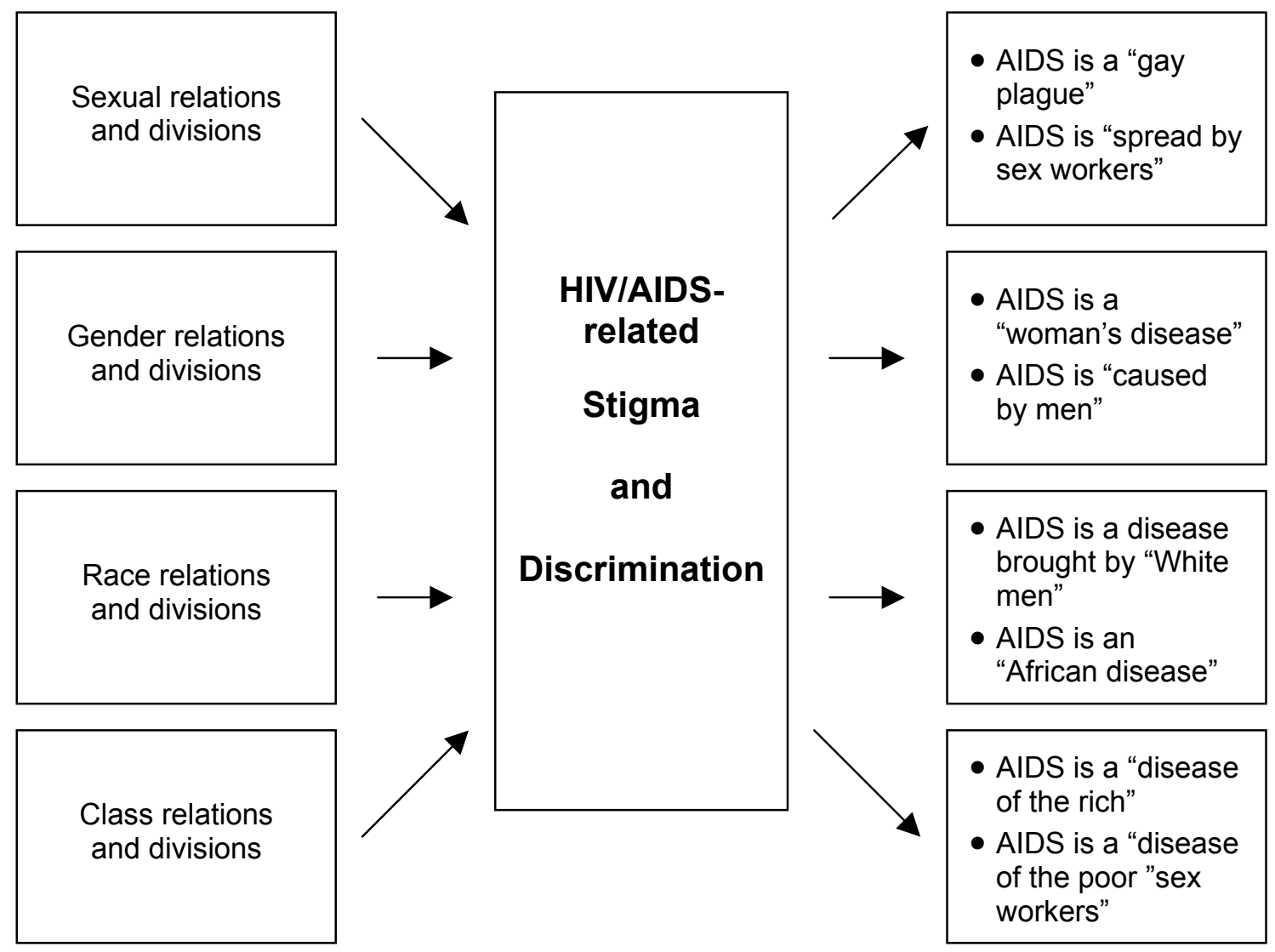

\section{Fear of contagion and disease}

HIV/AIDS is a life-threatening illness that people are afraid of contracting. The various metaphors associated with AIDS have also contributed to the perception of HIV/AIDS as a disease that affects "others," especially those who are already stigmatized because of their sexual behavior, gender, race, or socioeconomic status, and have enabled some people to deny that they personally could be at risk or affected (UNAIDS 2000; Malcolm et al. 1998; Daniel and Parker 1993).

HIV/AIDS-related S\&D is, therefore, the result of interaction between diverse pre-existing sources of $S \& D$ and fear of contagion and disease. The pre-existing sources, such as those related to 


\section{Hgrizons}

gender, sexuality, and class, often overlap and reinforce one another. This interaction has contributed to the deep-rooted nature of HIV/AIDS-related S\&D, limiting our ability to develop effective responses. It has also created a vicious circle of S\&D (see Figure 2), which works in two ways.

First, because HIV/AIDS is associated with marginalized behaviors and groups, all individuals with HIV/AIDS are assumed to be from marginalized groups and some may be stigmatized in a way that they were not before. For example, in some settings, men may fear revealing their HIV status because it will be assumed that they are homosexual. Similarly, women may fear revealing their serostatus because they may be labeled as "promiscuous" or sex workers and stigmatized as such. Second, HIV/AIDS exacerbates the stigmatization of individuals and groups who are already oppressed and marginalized, which increases their vulnerability to HIV/AIDS, and which in turn causes them to be further stigmatized and marginalized.

\section{Figure 2 The vicious circle of S\&D}

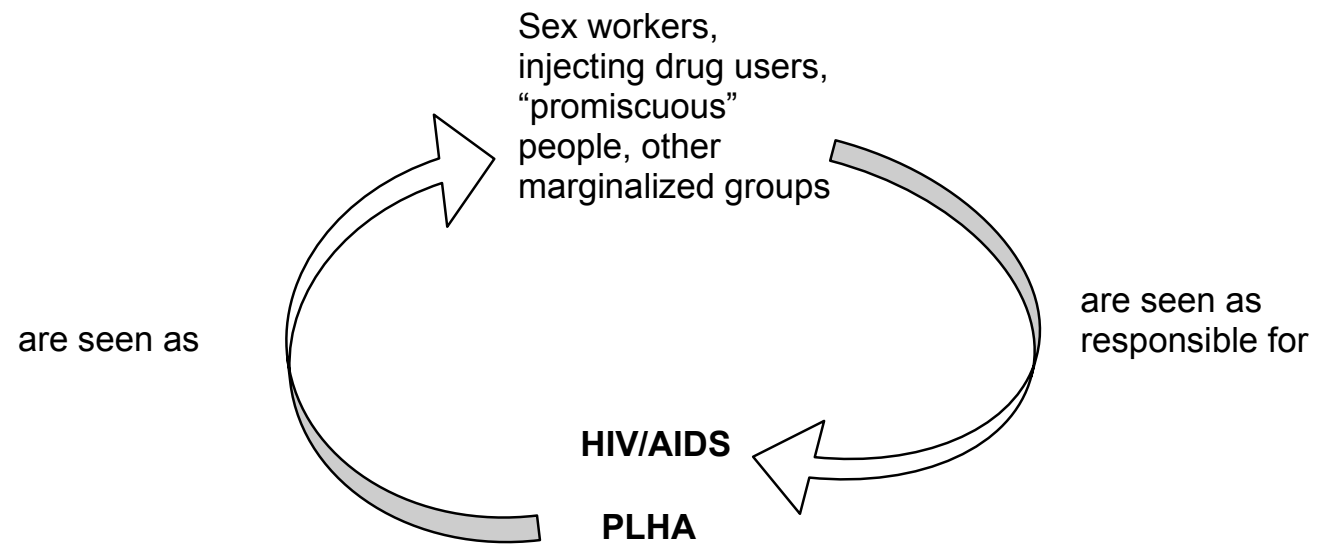

(1) HIVIAIDS is associated with marginalized behaviors, and people living with HIVIAIDS (PLHA) are stigmatized because they are assumed to be from marginalized groups.

(2) Already marginalized groups are further marginalized because they are assumed to have HIVIAIDS.

\section{How Are Stigma and Discrimination Manifested?}

HIV/AIDS-related S\&D take different forms and are manifested at different levels - societal, community and individual-and in different contexts (UNAIDS 2000; Malcolm et al. 1998). The following examples highlight where HIV/AIDS-related S\&D have been most frequently documented and where there is the greatest potential for interventions to reduce or mitigate $S \& D$. 


\section{HIVIAIDS-related Stigma}

\section{Policy and legal contexts}

HIV/AIDS-related S\&D in society is commonly manifested in the form of laws, policies, and administrative procedures, which are often justified as necessary to protect the "general population" (Kirp and Bayer 1992; Manuel et al. 1990). Examples of stigmatizing and discriminatory measures include compulsory screening and testing, compulsory notification of AIDS cases, restrictions of the right to anonymity, prohibition of PLHA from certain occupations, and medical examination, isolation, detention and compulsory treatment of infected persons (Tomasevski et al. 1992; Gostin and Lazzarini 1997).

One important example concerns limitations on international travel and migration. Despite widespread agreement that laws to prevent freedom of movement of people living with HIV/AIDS (PLHA) are ineffective public health measures, many countries have adopted policies restricting travel and migration. Discriminatory practices include mandatory HIV testing for individuals seeking work permits (AIDS Bhedbhav Virodhi Andolan 1993; Solon and Barrazo 1993), the requirement that individuals seeking tourist visas declare their HIV serostatus, and denial of entry to PLHA carrying medical drugs for HIV/AIDS treatment (Duckett and Orkin 1989). Foreigners have been deported from a diverse range of countries after the authorities have discovered that they are HIV-positive (Malcolm et al. 1998; AIDS Bhedbhav Virodhi Andolan 1993; Panos 1990).

HIV/AIDS-related S\&D reinforces existing prejudice toward foreigners or marginalized groups. For example, travelers from countries worst affected by the epidemic, or whose appearance makes others think they are gay men or sex workers, may be subject to additional questioning and physical searches. Foreign nationals engaged in sex work may be deported because of the risk they are said to pose to local clients. Early on in the epidemic, there were many reports of African students in Europe and Asia being detained or deported in this way (Sabatier 1988).

Some governments, recognizing that such measures are ineffective, have introduced legislation to protect the rights of PLHA to education, employment, confidentiality, information, and treatment (Kirp and Bayer 1992; Mann and Tarantola 1992; Mann, Tarantola, and Netter 1996). However, even when supportive legislation exists, it is not always enforced. The failure of governments to protect the rights of PLHA through legislation or to enforce existing legislation has been described as a form of discrimination by neglect (Daniel and Parker 1993; Watney 2000), as has the failure to provide effective prevention, treatment and care for those most vulnerable to HIV/AIDS and for PLHA.

\section{Institutional contexts}

\section{- Education and schools}

Children with HIV/AIDS or associated with HIV through infected family members have been stigmatized and discriminated against in educational settings in many countries. Stigma has led to teasing by classmates of HIV-positive school children or children associated with HIV (Gilborn et al. 2001). Discrimination against HIV-positive children in the USA and Brazil, including exclusion 


\section{Hgrizons}

from collective activities or expulsion from school, has led to non-discrimination legislation (Public Media Center 1995; Galvão 2000). However, less concern has been shown for young people who are perceived to be responsible for their HIV infection and who are already stigmatized and discriminated against because they are sexually active, homosexual, or drug users. In the USA, for example, HIV-positive young gay men have been expelled from school and, in some cases, subjected to violence (Kirp et al. 1989).

\section{- Employment and the workplace}

Such discriminatory practices as pre-employment screening, denial of employment to individuals who test positive, termination of employment of PLHA, and stigmatization of PLHA who are open about their serostatus (Gostin and Lazzarini 1997; Panos 1990; Barragán 1992; Gostin 1992; Panos 1992; Shisam 1993; Omangi 1997) have been reported from developed and developing countries. There have been reports of workers refusing to work next to those with HIV or AIDS or those perceived to be PLHA. Schemes providing medical assistance and pensions to employees have come under increasing pressure in countries seriously affected by HIV/AIDS, and some companies have used this as a reason to deny employment to PLHA (Williams and Ray 1993; Whiteside 1993). Few companies have developed strategies to combat S\&D or defined their responsibilities toward employees with HIV (Jackson and Pitts 1991; Bezmalinovic 1996).

\section{- Health care systems}

There have been many reports from health care settings of HIV testing without consent, breaches of confidentiality, and denial of treatment and care (AIDS Bhedbhav Virodhi Andolan 1993; Tirelli et al. 1991; Carvalho et al. 1993; Panebianco et al. 1994; Ogola 1990; Masini and Mwampeta 1993). Failure to respect confidentiality by clearly identifying patients with HIV/AIDS, revealing serostatus to relatives without prior consent, or releasing information to the media or police appear to be problems in some health services (Panos 1990; Bharat et al. 2001; Singh 1991). Factors contributing to these stigmatizing and discriminatory responses include lack of knowledge, moral attitudes, and perceptions that caring for PLHA is pointless because HIV/AIDS is incurable (Daniel and Parker 1993; Masini and Mwampeta 1993; Herek and Capitanio 1993; Herek et al. 1998; Blendon and Donelan 1988; Tesch, Simpson, and Kirby 1990; Rosasco Dulanto 1992; Cole, Zhang, and Chen 1993).

\section{- HIV/AIDS programs}

HIV/AIDS policies and programs may inadvertently contribute to stigmatization and discrimination by differentiating between the "general population" and "high-risk populations," prioritizing actions to prevent HIV spreading to the former from the latter. This approach is often justified in terms of avoiding stigmatization of "high-risk populations," since targeting such populations is believed to reinforce the association of HIV/AIDS with marginalized groups.

However, focusing on programs for the "general population" may also reinforce the perception that it is less important to protect populations that practice "high-risk" behaviors than the "innocent and 


\section{HIVIAIDS-related Stigma}

unsuspecting" general population. It may also result in discrimination against marginalized groups, since those at greatest risk do not receive the resources they need.

Furthermore, in some settings, allocating resources on the basis of acceptability rather than of need may be a deliberate policy, because of racism, homophobia, or negative attitudes toward marginalized groups (Panos 1996; Parker 2000). For example, government expenditure in most Latin American countries does not reflect the fact that HIV/AIDS has a disproportionate impact on homosexually and bisexually active men in these countries (Frasca et al. 2000).

\section{- Religious institutions}

In some contexts, HIV/AIDS-related S\&D has been reinforced by religious leaders and organizations, which have used their power to maintain the status quo rather than to challenge negative attitudes toward marginalized groups and PLHA. For example, at the international symposium Religious Health Organizations Break the Silence on HIV/AIDS, organized by the African Regional Forum of Religious Health Organizations during the $13^{\text {th }}$ International AIDS Conference in July 2000 (Singh 2001), it was noted that religious doctrines, moral and ethical positions regarding sexual behavior, sexism and homophobia, and denial of the realities of HIV/AIDS have helped create the perception that those infected have sinned and deserve their "punishment," increasing the stigma associated with HIV/AIDS.

\section{Community contexts}

In societies with cultural systems that place greater emphasis on individualism, HIV/AIDS may be perceived as the result of personal irresponsibility, and thus individuals are blamed for contracting the infection (Kegeles et al. 1989). In contrast, in societies where cultural systems place greater emphasis on collectivism, HIV/AIDS may be perceived as bringing shame on the family and community (Panos 1990; Warwick et al. 1998). The type of cultural system and where it fits along the continuum of individualism and collectivism will therefore influence the ways in which communities respond to HIV/AIDS and the ways in which S\&D are manifested.

Local cultural beliefs and explanations about disease and the causes of disease may also contribute to HIV/AIDS-related S\&D. For example, where illness is believed to be the result of "immoral" or "improper" behavior, HIV/AIDS may reinforce pre-existing stigma of those whose behavior is considered to be "deviant" (Warwick et al. 1998).

HIV/AIDS-related S\&D in families and communities is commonly manifested in the form of blame, scapegoating, and punishment. Communities often shun or gossip about those perceived to have HIV or AIDS. In more extreme cases, it has taken the form of violence (Nardi and Bolton 1991). For example, there have been reports from many countries of attacks on men who are assumed to be gay (Public Media Center 1995), of violence toward sex workers and street children in Brazil (Daniel and Parker 1993; Peterson 1990; Byrne 1992), and of HIV/AIDS-related murders in Colombia, India, Ethiopia, South Africa, and Thailand (Panos 1990; AFAO 1997). 


\section{Hgrizons}

\section{Family contexts}

The family is the main source of care and support for PLHA in most developing countries (Warwick et al. 1998; Aggleton and Warwick 1999; World Bank 1997). However, negative family responses are common. Infected individuals often experience S\&D in the home, and women are often more likely to be badly treated than men or children (Bharat and Aggleton 1999). Negative community and family responses to women with HIV/AIDS include blame, rejection, and loss of children and home (Parker and Galvão 1996; Bharat and Aggleton 1999; Henry 1990). Since HIV/AIDS-related S\&D reinforce and interact with pre-existing S\&D, families may reject PLHA not only because of their HIV status but also because HIV/AIDS is associated with promiscuity, homosexuality, and drug use (Panos 1990; Misra 1999; Mpundu 1999; Mujeeb 1999).

In many cases, HIV/AIDS-related S\&D has been extended to families, neighbors and friends of PLHA. This 'secondary' stigmatization and discrimination has played an important role in creating and reinforcing social isolation of those affected by the epidemic, such as the children and partners of PLHA.

\section{Individual contexts}

In individuals, the way in which HIV/AIDS-related S\&D are manifested depends on family and social support and the degree to which people are able to be open about such issues as their sexuality as well as their serostatus. In contexts where HIV/AIDS is highly stigmatized, fear of HIV/AIDS-related S\&D may cause individuals to isolate themselves to the extent that they no longer feel part of civil society and are unable to gain access the services and support they need (Daniel and Parker 1993). This has been called internalized stigma. In extreme cases, this has led to premature death through suicide (Gilmore and Somerville 1994; Hasan, Farag, and Elkerdawi 1994).

Even when laws exist to protect PLHA rights and confidentiality, few individuals are willing to litigate for fear that this will result in disclosure of their identity and HIV status. Given widespread negative community and family responses, many people choose not to know or reveal their serostatus.

Individuals who are already marginalized may be fearful of negative or hostile reactions from others, regardless of their serostatus (Daniel and Parker 1993; Panos 1990; Public Media Center 1995), reflecting the interaction between HIV/AIDS-related and pre-existing sources of S\&D. Fear of telling the family about their homosexuality has been cited by HIV-positive men in Mexico and Brazil as equal to the fear of revealing their serostatus. Similar fears have been reported from a range of countries by sex workers and injecting drug users (Castro et al. 1998a; Castro et al. 1998b; Terto 1999). Even when the family response is positive, fear of stigmatization and discrimination by the community may mean that an individual's serostatus is not revealed outside the home. 


\section{Developing a New Conceptual Framework}

\section{Why Do We Need a New Way of Thinking?}

As the discussion in the preceding section clearly demonstrates, HIV/AIDS-related S\&D are linked to the actions and attitudes of families, communities, and societies (UNAIDS 2000). However, current thinking largely focuses on S\&D as individual processes - or as what some individuals do to other individuals - rather than as social processes. The dominant definition describes stigma as a "discrediting attribute" and stigmatized individuals as those who possess an "undesirable difference," and ignores aspects that describe stigma as something that is socially constructed (Goffman 1963; Marshall 1998). This has resulted in the notion that stigma is a static individual feature or characteristic, limiting analysis of the underlying causes and possible responses to HIV/AIDS-related S\&D. We need to move beyond current thinking toward a conceptual framework that is based on an understanding that $S \& D$ are social processes and that, consequently, $\mathrm{S} \& \mathrm{D}$ can be resisted and challenged by social action.

\section{Understanding stigmatization and discrimination as social processes}

Social and political theory can help us to understand that stigmatization and discrimination are not isolated phenomena or the expression of individual attitudes, but are social processes used to create and maintain social control and to produce and reproduce social inequality.

\section{- S\&D are used to create "difference" and social hierarchy.}

Stigma is something that is "produced" and used to help order society. For example, most societies achieve conformity by contrasting those who are "normal" with those who are "different" or "deviant." Cultures therefore produce "difference" in order to achieve social control. In many nonWestern societies, local knowledge systems may perform the same function at a more localized level (Geertz 1983).

Similarly, concepts of symbolic violence and hegemony highlight the role of stigmatization in establishing social order and control, and identify stigmatization as part of the social struggle for power. Symbolic violence is a process where words, images and practices promote the interests of dominant groups (Bourdieu 1977; Bourdieu 1984; Bourdieu and Passeron 1977), and hegemony is achieved through the use of political, social and cultural forces to promote dominant meanings and values that legitimize unequal social structures (Foucault 1977 and 1978; Gramsci 1970; Williams 1977; Williams 1982). So all cultural meanings and practices embody interests and are used to enhance social distinctions between individuals, groups, and institutions.

Sociological analyses of discrimination are also useful because they emphasize the structural aspects of discrimination and "concentrate on patterns of dominance and oppression, viewed as expressions of a struggle for power and privilege" (Marshall 1998). 


\section{Hgrizons}

- S\&D are used to produce, legitimize, and perpetuate social inequality.

Following from the notion that stigmatization is a process that involves identifying differences between groups of people, and using these differences to determine where groups fit into structures of power, is the idea that stigma and discrimination are used to produce and reproduce social inequality. Stigmatization, therefore, not only helps to create difference but also plays a key role in transforming difference based on class, gender, race, ethnicity, or sexuality into social inequality.

Stigmatization is also used by dominant groups to legitimize and perpetuate inequalities, and concepts of symbolic violence and hegemony can also help us understand how it is that those who are stigmatized and discriminated against so often accept, and even internalize, the stigma to which they are subjected. This is because the processes of symbolic violence and hegemony convince the dominated to accept existing hierarchies and allow social hierarchies to persist over generations, without generating conscious recognition from those who are dominated. In addition, these processes limit the ability of oppressed and stigmatized groups and individuals to resist the forces that discriminate against them.

\section{Responding to stigmatization and discrimination through social action}

An understanding of stigmatization and discrimination as political and social processes can also help us to reconsider responses to HIV/AIDS-related S\&D.

For example, identity theory suggests that those who are stigmatized can take action to resist the forces that discriminate against them (Castells 1997; Hall 1990). Those who are marginalized generate "resistance identities" and use them to build a new identity that redefines their position in society and thus seeks the transformation of overall social structure. This would include resistance through mobilization of movements, at community, national, and international levels, aimed at social change.

\section{What are the implications for reconceptualizing S\&D?}

These ideas offer important insights for reconceptualizing HIV/AIDS-related stigmatization and discrimination within a broader social, cultural, political, and economic framework rather than as individual processes. They offer a framework for understanding S\&D as social processes that are used to create a social hierarchy by differentiating between the stigmatized and the nonstigmatized, as well as to produce and reproduce social inequalities and to make these inequalities seem reasonable.

Such a framework improves our ability to analyze the causes of S\&D and the ways in which HIV/AIDS S\&D interact with and reinforce pre-existing S\&D and social exclusion. More important, a better understanding of the processes that produce $S \& D$, as well as of the processes that produce resistance to $S \& D$, would enable us to develop more effective responses to HIV/AIDS-related S\&D. 


\section{Identifying an Agenda for Research and Intervention}

A new way of thinking has implications for the way in which research and interventions to address HIV/AIDS-related S\&D are framed and implemented. It implies the need for a broader approach, in which existing conceptual frameworks and intervention models that focus on the individual are complemented by:

- New approaches to research: ways of understanding HIV/AIDS-related S\&D that take account of social, cultural, political, and economic determinants.

- New approaches to programming and interventions: ways of responding to HIV/AIDS-related S\&D that engage societies, communities, and those who suffer stigmatization and discrimination.

\section{What Are the Implications for Research?}

Further development of the conceptual framework proposed in this paper would encourage research in three areas: exploratory and hypothesis-generating studies to inform investigative studies, investigative studies to inform policy and strategy, and strategic and policy-oriented studies to inform program implementation. Such research would emphasize in-depth work that focuses on the social context rather than studies that examine the behavioral and psychological dimensions of HIV/AIDS-related S\& D. The ultimate purpose of this research, including exploratory and investigative studies that are not directly linked to interventions, should be to support the development of policies and programs that will reduce HIV/AIDS-related S\&D.

\section{Exploratory and hypothesis-generating studies}

Research is required:

- To identify the environmental or structural sources of S\&D and the ways in which they are manifested through case studies and qualitative community research.

- To identify and develop new concepts and understanding that encompass the social, cultural, political, and economic determinants and consequences of HIV/AIDS-related S\&D, and that will be relevant for policies and programs in different cultures and contexts.

- To review the adequacy and appropriateness of concepts and understanding over time, in the light of changing needs, priorities, and circumstances that have an impact on HIV/AIDSrelated $\mathrm{S} \& \mathrm{D}$.

- To contribute to understanding of the processes of change, social movements, and cultural transformation in response to HIV and AIDS-related S\&D. 


\section{Hgrizons}

\section{Investigative studies}

Research is required:

- To investigate social processes in a range of different contexts to enable comparisons to be made and to develop an understanding of aspects of HIV/AIDS-related S\&D that are locally specific, as well as aspects that cut across cultural and national boundaries. ${ }^{2}$

- To identify opportunities and future priorities for intervention, including environmental and structural interventions.

- To provide insights into the reasons for the successes and failures of interventions intended to reduce S\&D. This requires identifying new tools for evaluating environmental and structural interventions. $^{3}$

- To investigate other strategies and interventions, such as home-based care, family counseling, and availability of effective treatment, that are not primarily intended to address S\&D but may do so indirectly, to assess the extent to which they contribute to reducing S\&D.

\section{Strategic and policy-oriented studies}

Research is required:

- To identify the policy and program elements and interventions that contribute to effective responses to HIV/AIDS-related S\&D.

- To identify how these can best be put into operation and the likely outcomes of specific approaches to program implementation.

- To improve understanding of how program implementation and the potential for replication and scaling up of successful approaches are influenced by the broader policy and social context.

\footnotetext{
${ }^{2}$ Recent studies, for example, of HIV/AIDS-related S\&D in India and Uganda (12), have shown that it is possible to conduct investigative research that allows for both specificity and comparability.

${ }^{3}$ The most commonly used evaluation approaches in the field of HIV/AIDS, which mainly assess changes at the individual level, need to be complemented by additional approaches capable of assessing community, social and structural variables. Such approaches could include comparative investigations together with carefully designed case studies, in order to draw general conclusions about the impact of environmental and structural interventions.
} 


\section{What Are the Implications for Interventions?}

Responding to HIV/AIDS-related S\&D as manifestations of power, inequality, and exclusion implies developing environmental and structural interventions (see Table 1) to change the context within which individuals and communities respond to HIV/AIDS (Parker, Easton, and Klein 2000; Sweat and Denison 1995), in addition to individual interventions. Individual psychological approaches alone will not achieve changes in S\&D and must be complemented by action to address structural and environmental constraints.

\section{Environmental change}

Issues to consider include developing programs that aim to achieve social and community change rather than just individual behavior change, drawing on the experience of community mobilization and social transformation in other areas (Parker 1996). Priority should be given to approaches that aim to strengthen capacity for resistance among stigmatized and marginalized groups, since empirical evidence indicates that some of the most effective responses to the HIV/AIDS epidemic have been those where affected communities have mobilized themselves to fight stigma, discrimination, and oppression (Daniel and Parker 1993; Altman 1994; Epstein 1996; Parker et al. 1995; Stoller 1998).

Particular attention should be paid to learning lessons from the experience of community organization and of empowering or "unleashing the power of resistance" of stigmatized populations and communities. Examples relevant to HIV/AIDS include the Greater Involvement of People Living with or Affected by HIV/AIDS (GIPA) principle (it is a principle and must be named as such - see UNAIDS website, www.unaids.org, and other locations), which promotes the active involvement of PLHA in government ministries and civil society organizations to both empower PLHA and to encourage positive perceptions of PLHA, and support for PLHA organizations and networks, which have enabled people living with HIV/AIDS to demand recognition of their existence, needs, and rights. Organizing has also enabled those who are marginalized to challenge discrimination and to lobby for changes in laws and policies. For example, sex worker unions have challenged police persecution, gay men's organizations have played a significant role in advocating for access to treatment, and women's organizations have lobbied for changes in the inheritance rights of widows.

Such activities, designed to empower marginalized groups, should complement ongoing efforts to change individual attitudes toward PLHA and those affected by the epidemic through, for example, media campaigns promoting tolerance and compassion. Useful lessons could be learned from efforts to address S\&D associated with other issues, such as mental health and leprosy. In Scotland, for example, providing the community with information and encouraging greater day-to-day contact with people with mental illness helped to reduce stigmatization of mental illness (Brunton 1977), and a national campaign in the UK to educate the public about mental illness resulted in more positive attitudes and greater willingness to seek treatment from health professionals (Paykel, Hart, and Priest 1998). In Tanzania, a health education campaign designed to reduce the stigma of 


\section{Hgrizons}

leprosy improved community attitudes in terms of, for example, greater willingness to share food or shake hands with a person with leprosy (Van den Broek et al. 1998).

Finally, there is a need to develop advocacy models to address HIV/AIDS-related S\&D, drawing on the experience of community mobilization, empowerment, and social transformation.

\section{Structural change}

Priority should be given to developing a legal and policy framework that protects the human rights of PLHA and those affected by the epidemic and that helps to mitigate the impact of HIV/AIDSrelated S\&D. Useful lessons about structural interventions are available from countries that have implemented protective legal and policy frameworks, such as the 100 percent condom programs in Thailand, Cambodia, and the Dominican Republic, where the government introduced policies requiring bar owners to promote condom use by clients of sex workers. This approach appears to have changed social norms toward unprotected sex with sex workers and, more important, provided structural protection to enable sex workers to negotiate condom use.

Table 1 Levels of S\&D and intervention responses

\begin{tabular}{|l|l|l|l|}
\hline Causal level & Definition & Examples & Change mechanism \\
\hline $\begin{array}{l}\text { Super- } \\
\text { structural }\end{array}$ & $\begin{array}{l}\text { Macrosocial and } \\
\text { political } \\
\text { arrangements, } \\
\text { resource and power } \\
\text { differences }\end{array}$ & $\begin{array}{l}\text { Gender inequalities, } \\
\text { homophobia, poverty, } \\
\text { economic underdevelopment }\end{array}$ & $\begin{array}{l}\text { Social movements, } \\
\text { empowerment of } \\
\text { disenfranchised } \\
\text { groups and } \\
\text { populations }\end{array}$ \\
\hline Structural & Laws and policies & $\begin{array}{l}\text { Lack of or poor implementation } \\
\text { of human rights laws; laws that } \\
\text { promote discrimination, e.g., } \\
\text { restrictions on travel and } \\
\text { migration }\end{array}$ & $\begin{array}{l}\text { Legislative lobbying, } \\
\text { civil and human rights } \\
\text { activism, legal reform }\end{array}$ \\
\hline Environmental & $\begin{array}{l}\text { Living conditions, } \\
\text { resources and } \\
\text { opportunities }\end{array}$ & $\begin{array}{l}\text { Lack of rights in workplace, } \\
\text { lack of access to information } \\
\text { and services }\end{array}$ & $\begin{array}{l}\text { Provision of social } \\
\text { and health services, } \\
\text { community } \\
\text { organization, } \\
\text { unionization }\end{array}$ \\
\hline Individual & $\begin{array}{l}\text { How the environ- } \\
\text { ment is experienced } \\
\text { and acted upon by } \\
\text { individuals }\end{array}$ & $\begin{array}{l}\text { Fear of negative reactions by } \\
\text { others, lack of knowledge, low } \\
\text { risk perception, moral values }\end{array}$ & $\begin{array}{l}\text { Education, } \\
\text { counseling, improved } \\
\text { self-efficacy }\end{array}$ \\
\hline
\end{tabular}

* Adapted from Sweat and Denison 1995. 


\section{Summary}

Efforts to tackle HIV/AIDS-related stigma and discrimination have been constrained by the complexity and deep-rooted nature of the problem. More specifically, the development of effective responses to HIV/AIDS-related S\&D has been limited by the inadequacy of available theoretical and methodological tools, which tend to focus on stigmatization and discrimination as individual processes - what some individuals do to other individuals. This paper argues that we need a new way of thinking about stigma and discrimination to improve our ability both to analyze the processes that produce $\mathrm{S} \& \mathrm{D}$ and to address these processes.

The paper suggests that we need to acknowledge the way in which HIV/AIDS-related S\&D interact with and reinforce pre-existing S\&D associated with sexuality, gender, race, and poverty, and to locate HIV/AIDS-related S\&D within a broader social, cultural, political, and economic framework. It proposes a conceptual framework that defines S\&D as social processes - which are used to create and maintain social control and to produce and reproduce structural inequalitiesrather than as individual actions. It describes stigmatization as a process that involves identifying and using "difference" between groups of people to create and legitimize social hierarchies, and explains how stigma plays a key role in transforming difference into social inequalities. It further demonstrates how enacted stigma — or discrimination — helps to perpetuate these inequalities.

Such a framework implies new approaches to research, including exploratory studies to identify and assess concepts that take account of the social, cultural, political, and economic determinants of S\&D and contribute to our understanding of the processes of change; investigative studies to explore these processes in a range of contexts and evaluate the potential of interventions intended to reduce S\&D; and strategic and policy-oriented studies to inform implementation of effective responses.

Such a framework also implies new approaches to program development and intervention that engage societies, communities, and those who experience stigma and discrimination. If S\&D are understood to be the products of social rather than individual processes, it follows that challenging S\&D requires social action to change the context within which individuals and communities respond to HIV/AIDS rather than just individual action. Creating a climate in which S\&D are no longer tolerated therefore requires environmental interventions - in particular, social and community mobilization and empowerment of marginalized groups to resist S\&D - and structural interventions, especially laws and policies that protect the rights of PLHA and those affected by the HIV/AIDS epidemic. 


\section{Hgrizons}

\section{References}

AIDS Bhedbhav Virodhi Andolan (AIDS Anti-Discrimination Movement). 1993. Hard Times for Positive Travel. India, New Delhi.

AFAO (Australian Federation of AIDS Organizations). 1997. "Human rights: from policy to practice," National AIDS Bulletin 11(5):28-29.

Aggleton, P. and I. Warwick. 1999. Household and Community Responses to HIV and AIDS in Developing Countries: Findings from Multi-site Studies: Geneva, UNAIDS.

Altman, D. 1994. Power and Community: Organizational and Cultural Responses to AIDS. London: Taylor and Francis.

Barragán, E.M. 1992. "VIH/SIDA y Trabajo - Fragmentos a Debate,” Sociedad y SIDA 21:1-4.

Bezmalinovic, B. 1996. "The private sector, how are the corporations responding to HIV/AIDS?," in AIDS in the World II, ed. J. Mann and D.J.M. Tarantola. New York: Oxford University Press.

Bharat, S. with P.J. Aggleton and P. Tyrer. 2001. India: HIV and AIDS-related Discrimination, Stigmatisation and Denial. UNAIDS Best Practice Collection.

Bharat, S. and P. Aggleton. 1999. "Facing the challenge: Household responses to AIDS in India," AIDS Care 11:33-46.

Blendon, R.J. and K. Donelan. 1988. "Discrimination against people with AIDS," American Journal of Public Health 319:1022-1026.

Bourdieu, P. 1977. Outline of a Theory of Practice. Cambridge: Cambridge University Press. 1984. Distinction: A Social Critique of the Judgement of Taste. Cambridge: Cambridge University Press.

Bourdieu, P. and J-C. Passeron. 1977. Reproduction in Education, Society and Culture. London: Sage.

Brunton, K. 1977. “Stigma,” Journal of Advanced Nursing 26: 891-898.

Byrne, L. 1992. “Health risks of Rio’s street children,” British Medical Journal 304:1459-50.

Carvalho, A.P. et al. 1993. The fight against discrimination by private health insurers, report of Rio de Janeiro experience, abstract, IXth International Conference on AIDS and IVth STD World Congress, Berlin. 
Castells, M. 1996. The Network Society. Oxford: Blackwell Publishers, Inc.

— 1997. The Power of Identity. Oxford: Blackwell Publishers, Inc.

. 1998. End of Millenium. Oxford: Blackwell Publishers, Inc.

Castro, R. et al. 1998a. "Family responses to HIV/AIDS in Mexico," Social Science and Medicine 47(10):1473-1484.

Castro, R. et al. 1998b. "AIDS-related illness trajectories in Mexico: findings from a qualitative study in two marginalized communities," AIDS Care 10:583-98.

Cole, B.L., Z. Zhang, and C.Z. Chen. 1993. "HIV-related knowledge and attitudes among medical students in China," AIDS Care 5(3):305-312.

Daniel, H. and R. Parker. 1993. Sexuality, Politics and AIDS in Brazil. London: Falmer Press.

Duckett, M. and A. Orkin. 1989. "AIDS-related migration and travel policies and restrictions-A global survey.” AIDS 3(suppl. 1):S231-252.

Epstein, S. 1996. Impure Science: AIDS, Activism and the Politics of Knowledge. Berkeley and Los Angeles: University of California Press.

Foucault, M. 1977. Discipline and Punish. New York: Pantheon.

. 1978. The History of Sexuality, Volume I: An Introduction. New York: Random House.

Frasca, T. et al. 2000. Needs assessment for HIV prevention among gay and bisexual men in three provincial capitals of Chile. Oral presentation at the $13^{\text {th }}$ International Conference on AIDS, Durban, South Africa, July, 2000, Abstract ThOrD736.

Gagnon, J.H. and W. Simon. 1973. Sexual Conduct. Chicago: Aldine.

Galvão, J. 2000. AIDS no Brasil. São Paulo and Rio de Janeiro: Editora 34/ABIA.

Geertz, C. 1983. Local Knowledge. New York: Basic Books.

Gilborn, L. et al. 2001. Making a Difference for Children Affected by AIDS: Baseline Findings from Operations research in Uganda. Washington, DC: Population Council.

Gilmore, N. and M.A. Somerville. 1994. "Stigmatisation, scapegoating and discrimination in sexually transmitted diseases, overcoming 'them' and 'us'," Social Science and Medicine 39:13391358. 


\section{Hgrizons}

Goffman, E. 1963. Stigma: Notes on the Management of a Spoiled Identity. New York: Simon and Schuster.

Gostin, L. 1992. "The AIDS Litigation Project, a national review of court and Human Rights Commission decisions on discrimination," in AIDS, the Making of a Chronic Disease, ed. E. Fee and D.M. Fox. Los Angeles, University of California Press.

Gostin, L.O. and Z. Lazzarini. 1997. Human Rights and Public Health in the AIDS Pandemic. New York: Oxford University Press.

Gramsci, A. 1970. Prison Notebooks. London: Lawrence and Wishart.

Hall, S. 1990. "Cultural identity and diaspora," in Identity: Community, Culture, Difference, ed. J. Rutherford. London: Lawrence and Wishart.

Hasan, M.A., A.B. Farag, and M.M. Elkerdawi. 1994. Human rights of HIV infected persons/PLAs in Egypt, abstract, Xth International Conference on AIDS, Yokohama, Japan.

Henry, N. 1990. "Africans, facing AIDS, haltingly talk of it, Tanzanian counsel service," Washington Post, 17 September:A17-18.

Herek, G.M. and J.P. Capitanio. 1993. "Public reactions to AIDS in the United States, a Second decade of stigma," American Journal of Public Health 83(4):574-577.

Herek, G. et al. 1998. "Workshop report: AIDS \& stigma: a conceptual framework and research agenda," AIDS \& Public Policy Journal 13(1):36-47.

Jackson, H. and M. Pitts. 1991. "Company policy and AIDS in Zimbabwe," Journal of Social Development in Africa 6:53-70.

Kegeles, S.M. et al. 1989. "Perceptions of AIDS, the continuing saga of AIDS-related stigma," AIDS 3(suppl.1):S253-S258.

Kirp, D.L. and R. Bayer (ed.). 1992. AIDS in the Industrialized Democracies. New Brunswick, NJ: Rutgers University Press.

Kirp, D. et al. 1989. Learning By Heart: AIDS and Schoolchildren in America's Communities. New Brunswick, NJ: Rutgers University Press.

Malcolm, A. et al. 1998. "HIV and AIDS-related stigmatization and discrimination: its form and contexts," Critical Public Health 8(4):347-370.

Mann, J. 1987. Statement at an informal briefing on AIDS to the 42nd Session of the United Nations General Assembly, 20 October, New York. 
Mann, J. and D.J.M. Tarantola (ed.). 1996. AIDS in the World II. New York: Oxford University Press.

Mann, J., D.J.M. Tarantola, and T.W. Netter (ed.). 1992. AIDS in the World. Boston, MA: Harvard University Press.

Manuel, C. et al. 1990. "The ethical approach to AIDS, a bibliographical review," Journal of Medical Ethics 16:14-27.

Marshall, G. 1998. Oxford Dictionary of Sociology. Oxford and New York: Oxford University Press.

Masini, T. and S. Mwampeta. 1993. "Societal response - discrimination and stigmatisation in Tanzania," abstract, IXth International Conference on AIDS and IVth STD World Congress, Berlin.

Misra, S. 1999. "Social discrimination and rejection in Cambodia," posting to SEA-AIDS, Tue, 29 Jun 1999.

Mpundu, M. 1999. "Ignorance, denial, fear and violence: stigmatisation and discrimination in African communities-Zambia," posting to SEA-AIDS.

Mujeeb, S. 1999. "Human right violations of PLWA/HIV by their family members," posting to SEA-AIDS, Tue, 06 Jul 1999.

Nardi, P.M. and R. Bolton. 1991. "Gay-bashing, violence and aggression against gay men and lesbians," in Targets of Violence and Aggression, ed. R. Baenninger. North-Holland: Elsevier.

Ogola, H. 1990. "Tanzania, hope in the extended family," in The 3rd Epidemic, Repercussions of the Fear of AIDS. London: Panos Institute.

Omangi, H.G. 1997. "Stigmatization and discrimination in the context of HIV and AIDS in Kenya," Newsletter of African Network on Ethics, Law and HIV 3:4-5.

Panebianco, S. et al. 1994. "Human rights violations and AIDS, two parallel public health epidemics," abstract submitted to Xth International Conference on AIDS and International Conference on STDs, Yokohama, Japan, 7-12 August.

PANOS. 1990. The 3rd Epidemic: Repercussions of the Fear of AIDS. London: Panos Institute. Institute. 1992. The Hidden Cost of AIDS: The Challenge of HIV to Development. London: Panos 1996. On the Margins: Men Who Have Sex with Men and HIV in the Developing World. London: Panos Institute. 


\section{Hgrizons}

Parker, R. 2000. "Administering the epidemic: HIV/AIDS policy, models of development and international health in the late-twentieth century," in Globalization, Health and Identity: The Fallacy of the Level Playing Field, ed. L.M. Whiteford and L. Manderson. Boulder, CO: Lynne Rienner Publishing, pp. 39-55.

Parker, R.G. 1996. Empowerment, community mobilisation and social change in the face of HIV/AIDS. AIDS 10(suppl. 3):S27-S31.

Parker R.G., D. Easton, and C. Klein. 2000. "Structural barriers and facilitators in HIV prevention: a review of international research," AIDS 14(Suppl. 1):S22-S32.

Parker, R.G. and J. Galvão (ed.). 1996. Quebrando o Silêncio: Mulheres e AIDS no Brasil. Rio de Janeiro: Editora Relume-Dumará.

Parker, R.G. et al. 1995. "AIDS prevention and gay community mobilisation in Brazil," Development 2:49-53.

Paykel, E.S, D. Hart, and R.G. Priest. 1998. "Changes in public attitudes to depression during the Defeat Depression Campaign,” British Journal of Psychiatry 173(12): 519-522.

Peterson, C. 1990. "Prostitutes and public health services co-operate on AIDS prevention in Brazil," Hygiene 9:29-31.

Piot, P. 2000. Report by the Executive Director. Programme Co-ordinating Board. Joint United Nations Programme on AIDS. Rio de Janeiro. 14-15 December.

Plummer, K. 1975. Sexual Stigma: An Interactionist Approach. London: Routledge and Kegan Paul.

Public Media Center. 1995. The Impact of Homophobia and Other Social Biases on AIDS. A Special Report by the Public Media Center, San Francisco, California.

Rosasco Dulanto, A.M. 1992. "Conocimientos y Actitudes sobre el Sida de Trabajadores Asistenciales en tres Instituciones de Salud en Lima, Peru," in A Portfolio of AIDS/STD Behavioral Interventions and Research, ed. L. Bond. Washington, DC: Pan-American Health Organization.

Sabatier, R. 1988. Blaming Others. London: The Panos Institute.

Shisam, K. 1993. "What AIDS policy options does India require now?," CARC Calling 6(2):29-32.

Singh, B. 2001. "Breaking the silence on HIV/AIDS: religious health organisations and reproductive health," Conscience, Catholics for a Free Choice.

Singh, N.K. 1991. "AIDS and society," Health for the Millions 17:29-30. 
Solon, O. and A. Barrazo. 1993. "Overseas contract workers and economic consequences of HIV and AIDS in the Philippines," in Economic Implications of AIDS in South East Asia, ed. D. Bloom and J. Lyons. New Delhi: UNDP.

Stoller, N. 1998. Lessons from the Damned: Queers, Whores, and Junkies Respond to AIDS. New York and London: Routledge.

Sweat, M. and J. Dennison. 1995. "Reducing HIV incidence in developing countries with structural and environmental interventions," AIDS 9(suppl. A):S225-257.

Terto Jr., V. 1999. "Seropositivity, homosexuality and identity politics in Brazil," Culture, Health and Sexuality 1(4):329-346.

Tesch, B.J., D.E. Simpson, and B.D. Kirby. 1990. "Medical and nursing students' attitudes about AIDS issues," Academic Medicine 65(7):467-469.

Tirelli, U. et al. 1991. "HIV and discrimination," British Medical Journal 303:582 (letter).

Tomasevski, K. et al. 1992. "AIDS and human rights," in AIDS in the World, ed. J. Mann, D.J.M. Tarantola, and T.W. Netter. Boston, MA: Harvard University Press.

UNAIDS. 2000. "HIV and AIDS-related stigmatisation, discrimination and denial: forms, contexts and determinants," research studies from Uganda and India (prepared for UNAIDS by Peter Aggleton). Geneva, UNAIDS.

USAID. 2000. USAID Concept Paper: Combating HIV/AIDS Stigma, Discrimination and Denial: What Way Forward?. Unpublished paper. June $23^{\text {rd }}, 2000$.

Van den Broek, J. et al. 1998. "Evaluation of a sustained 7-year health education campaign on leprosy in Rufiji District, Tanzania," Leprosy Review 69: 57-74.

Warwick, I. et al. 1998. "Household and community responses to AIDS in developing countries," Critical Public Health 8(4):291-310.

Watney, Simon. 2000. Imagine Hope: AIDS and Gay Identity. London and New York: Routledge

Weeks, J. 1981. Sex, Politics and Society: The Regulation of Sexuality since 1800. New York: Longman.

Whiteside, A. 1993. "The impact of AIDS on industry in Zimbabwe," in Facing up to AIDS, the Socio-economic Impact in Southern Africa, ed. S. Cross and A. Whiteside. New York: St Martin's Press. 


\section{Hgrizons}

Williams, G. and S. Ray. 1993. Work against AIDS, Workplace-based AIDS Initiatives in Zimbabwe, Strategies for Hope No.8, London: ActionAid.

Williams, R. 1977. Marxism and Literature. Oxford: Oxford University Press.

- 1982. The Sociology of Culture. New York: Schoken Books.

World Bank. 1997. Confronting AIDS: Public Priorities in a Global Epidemic. New York: Oxford University Press. 


\section{Hgrizons}

Horizons is a global operations research program designed to:

- Identify and test potential strategies to improve HIV/AIDS prevention, care, and support programs and service delivery.

-Disseminate best practices and utilize findings with a view toward scaling up successful interventions.

For more information, please contact:

Horizons Program, Communications Unit 4301 Connecticut Avenue, NW Suite 280 Washington, DC 20008 USA

Tel: 202-237-9400

Fax: 202-237-8410

Email: horizons@pcdc.org

www.popcouncil.org/horizons/horizons.html

\section{Population Council}

Horizons is implemented by the Population Council in collaboration with - International Center for Research on Women (ICRW)

- International HIV/AIDS Alliance

- Program for Appropriate Technology in Health (PATH)

- Tulane University

- University of Alabama at Birmingham

- Family Health International (FHI) - Johns Hopkins University 